\title{
Reducing Unnecessary Testing in the Intensive Care Unit by Choosing Wisely
}

\author{
Ruth M. Kleinpell ${ }^{1,2}$, J. Christopher Farmer ${ }^{3}$, and Stephen M. Pastores ${ }^{4}$ \\ Vanderbilt University Medical Center and School of Nursing, Nashville, TN; ${ }^{2}$ Rush University Medical Center and College of Nursing, Chicago, IL; ${ }^{3}$ Mayo Clinic, Phoenix, AZ; \\ ${ }^{4}$ Critical Care Center, Department of Anesthesiology and Critical Care Medicine, Memorial Sloan Kettering Cancer Center, New York, NY, USA
}

Overuse of laboratory and X-ray testing is common in the intensive care unit (ICU). This review highlights focused strategies for critical care clinicians as outlined by the Critical Care Societies Collaborative (CCSC) as part of the American Board of Internal Medicine Foundation's Choosing Wisely ${ }^{\circledR}$ campaign. The campaign aims to promote the use of judicious testing and decrease unnecessary treatment measures in the ICU. The CCSC outlines five specific recommendations for reducing unnecessary testing in the ICU. First, reduce the use of daily or regular interval diagnostic testing. Second, do not transfuse red blood cells in hemodynamically stable, non-bleeding ICU patients with a hemoglobin concentration greater than $7 \mathrm{mg} / \mathrm{dl}$. Third, do not use parenteral nutrition in adequately nourished critically ill patients within the first 7 days of ICU stay. Fourth, do not deeply sedate mechanically ventilated patients without a specific indication and without daily attempts to lighten sedation. Finally, do not continue life support for patients at high risk of death without offering patients and their families the alternative of comfort focused care. A number of strategies can be used to reduce unnecessary testing in the ICU, including educational campaigns, audit and feedback, and implementing prompts in the electronic ordering system to allow only acceptable indications when ordering routine testing. Greater awareness of the lack of outcome benefit and associated costs can prompt clinicians to be more mindful of ordering tests and procedures in order to reduce unnecessary testing in the ICU.

Key Words: Choosing Wisely; intensive care units; laboratory testing; X-ray testing

\section{OVERVIEW}

Hospitalization in an intensive care unit (ICU) typically requires extensive diagnostic testing and procedures as a component of the management of critical illness. Daily laboratory and X-ray testing are commonly performed in the ICU for diagnosis and/or monitoring of critically ill patients as well as assessing their response to treatment. Critical care professionals fear missing important clinical changes in patient status. Despite the absence of supporting data, we commonly react by ordering frequent testing, hoping to improve detection of subtle but important physiological changes. It has been demonstrated that up to $48 \%$ of laboratory tests performed routinely in the ICU have normal results [1]. Fortunately, greater awareness of the lack of outcome benefit and increased costs associated with obtaining daily laboratory tests and chest X-rays in the ICU has prompted clinicians to be more mindful of ordering tests and procedures in order

Received on February 5, 2018 Accepted on February 8, 2018

Correspondence to: Ruth M. Kleinpell, Vanderbilt University Medical Center, 905 20th Avenue South, \#1116N, Nashville, TN 37203, USA

Tel: +1-773-415-2495, Fax: +1-312-942-2320, E-mail: ruth.kleinpel|@vanderbilt.edu

*No potential conflict of interest relevant to this article was reported.

(c) This is an Open Access article distributed under the terms of the Creative Commons Attribution Non-Commercial License (http://creativecommons.org/ licenses/by-nc/4.0/) which permits unrestricted non-commercial use, distribution, and reproduction in any medium, provided the original work is properly cited. Copyright (c) 2018 The Korean Society of Critical Care Medicine 
to reduce unnecessary testing.

\section{CHOOSING WISELY ${ }^{\circledR}$}

To promote the use of judicious testing and decrease unnecessary treatment measures, the American Board of Internal Medicine Foundation established the Choosing Wisely ${ }^{\circledR}$ campaign in 2012 [2]. The Choosing Wisely ${ }^{\circledR}$ campaign tasked professional societies to develop lists of the top five medical services - test, procedures and treatments - commonly used but whose necessity should be questioned. More than eighty specialty organizations have prioritized recommendations to improve decision-making and promoted appropriate patient-centered care. Each society developed a list of five to ten tests, treatments, or services that are commonly overused [3]. Choosing Wisely ${ }^{\circledR}$ initiatives have included best practice campaigns, quality improvement projects, and formal research studies within the United States and globally. The Choosing Wisely Canada campaign has launched the 10 Million Challenge - a collective action initiative to prevent 10 million unnecessary tests and treatments across Canada by the year 2020 [4]. "Consumer Reports" is a partner in the Choosing Wisely ${ }^{\circledR}$ campaign and has collaborated with specialty societies to create patient education materials, including engaging brochures for consumers to reference for common health practices and treatments and specific questions to ask their healthcare provider [5].

\section{CHOOSING WISELY ${ }^{\circledR}$ AND CRITICAL} CARE

The Critical Care Societies Collaborative, composed of the four major critical care societies in the United States including the American Thoracic Society, the American College of Chest Physicians, the American Association of Critical-Care Nurses and Society of Critical Care Medicine, participated in the Choosing Wisely ${ }^{\circledR}$ campaign by developing ICU specific recommendations [6]. These recommendations include as follows. (1) Don't order diagnostic tests at regular intervals (such as every day), but rather in response to specific clinical questions. (2) Don't transfuse red blood cells in hemodynamically stable, nonbleeding ICU patients with a hemoglobin concentration greater than $7 \mathrm{mg} / \mathrm{dl}$. (3) Don't use parenteral nutrition in adequately nourished critically ill patients within the first 7 days of an ICU stay. (4) Don't deeply sedate mechanically ventilated patients without a specific indication and without daily attempts to lighten sedation. (5) Don't continue life support for patients at high risk for death or severely impaired functional recovery without offering patients and their families the alternative of care focused entirely on comfort. These recommendations and the rationale for targeting better care in the ICU are outlined in Figure 1.

\section{ICU FOCUSED CHOOSING WISELY ${ }^{\circledast}$ INITIATIVES}

In response to the Choosing Wisely ${ }^{\circledR}$ campaign, a number of reports have been published citing strategies for reducing unnecessary testing [7-9]. Unfortunately, only a limited number of these studies are specific to an ICU environment. A review of routine daily lab testing in the ICU identified five nonrandomized studies and one economic impact evaluation. Three of these studies implemented strategies to prevent long-term standing orders for routine biochemistry and hematology blood tests [10]. After implementing measures to reduce routine testing, these three studies all found that the number of routine laboratory tests decreased significantly, resulting in less iatrogenic anemia and substantial cost savings without compromising patient outcomes. Notably, when routine ICU blood tests were performed consecutively and daily, almost $50 \%$ of the results were normal and $32 \%$ were consecutively normal. Changing our practice of ordering consecutive routine blood tests that might not affect decision-making can have a significant impact for clinical care, especially in the ICU.

In a recent survey conducted by the Society of Critical 


\section{Choosing Wisely}

An initiative of the ABIM Foundation

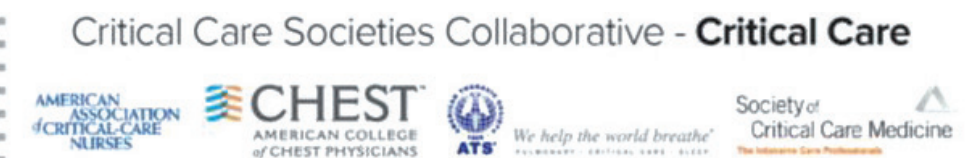

Five Things Physicians and Patients Should Question

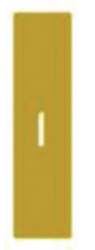

\section{Don't order diagnostic tests at regular intervals (such as every day),} but rather in response to specific clinical questions.

Many diagnostic studies (including chest radiographs, arterial blood gases, blood chemistries and counts and electrocardiograms) are ordered at regular intervals (e.g., daily). Compared with a practice of ordering tests only to help answer clinical questions, or when doing so will affect management, the routine ordering of tests increases health care costs, does not benefit patients and may in fact harm them. Potential harms include anemia due to unnecessary phlebotomy. which may necessitate risky and costly transfusion, and the aggressive work-up of incidental and non-pathological results found on routine studies.

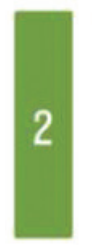

\section{Don't transfuse red blood cells in hemodynamically stable, non-bleeding} ICU patients with a hemoglobin concentration greater than $7 \mathrm{mg} / \mathrm{dL}$.

2 Most red blood cell transfusions in the ICU are for benign anemia rather than acute bleeding that causes hemodynamic compromise. For all patient populations in which it has been studied, transfusing red blood cells at a threshold of $7 \mathrm{mg} / \mathrm{dL}$ is associated with similar or improved survival, fewer complications and reduced costs compared to higher transfusion triggers. More aggressive transfusion may also limit the availability of a scarce resource. It is possible that different thresholds may be appropriate in patients with acute coronary syndromes, although most observational studies suggest harms of aggressive transfusion even among such patients.

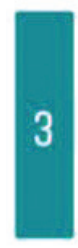

\section{Don't use parenteral nutrition in adequately nourished critically ill patients within the first seven days of an ICU stay.}

3 For patients who are adequately nourished prior to ICU admission, parenteral nutrition initiated within the first seven days of an ICU stay has been associated with harm, or at best no benefit, in terms of survival and length of stay in the ICU. Early parenteral nutrition is also associated with unnecessary costs. These findings are true even among patients who cannot tolerate enteral nutrition. Evidence is mixed regarding the effects of early parenteral nutrition on nosocomial infections. For patients who are severely malnourished directly prior to their ICU admission, there may be benefits to earlier parenteral nutrition.

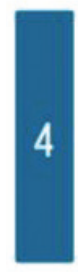

\section{Don't deeply sedate mechanically ventilated patients without a specific indication and without daily attempts to lighten sedation.}

Many mechanically ventilated ICU patients are deeply sedated as a routine practice despite evidence that using less sedation reduces the duration of mechanical ventilation and ICU and hospital length of stay. Several protocol-based approaches can safely limit deep sedation, including the explicit titration of sedation to the lightest effective level, the preferential administration of analgesic medications prior to initiating anxiolytics and the performance of daily interruptions of sedation in appropriately selected patients receiving continuous sedative infusions. Although combining these approaches may not improve outcomes compared to one approach alone, each has been shown to improve patient outcomes compared with approaches that provide deeper sedation for ventilated patients.

Don't continue life support for patients at high risk for death or severely impaired functional recovery without offering patients and their families the alternative of care focused entirely on comfort.

5 Patients and their families often value the avoidance of prolonged dependence on life support. However, many of these patients receive aggressive life-sustaining therapies, in part due to clinicians' failures to elicit patients' values and goals, and to provide patient-centered recommendations. Routinely engaging high-risk patients and their surrogate decision makers in discussions about the option of foregoing life-sustaining therapies may promote patients' and families' values, improve the quality of dying and reduce family distress and bereavement. Even among patients pursuing life-sustaining therapy, initiating palliative care simultaneously with ongoing disease-focused therapy may be beneficial.

Figure 1. Critical Care Society Collaborative’s Choosing Wisely ${ }^{\circledR}$ list for critical care. ICU: intensive care unit. Adapted from the Critical Care Societies Collaborative [6].

Care Medicine of over 400 physicians, approximately $75 \%$ indicated they were familiar with the Choosing Wisely ${ }^{\circledR}$ campaign and that a number of a specific institutional initiatives targeting at least one if not more of the
Critical Care Societies Collaborative's Choosing Wisely ${ }^{\circledR}$ recommendations for critical care had been implemented to target reducing unnecessary testing in the ICU (Figures 2 and 3) [11]. 


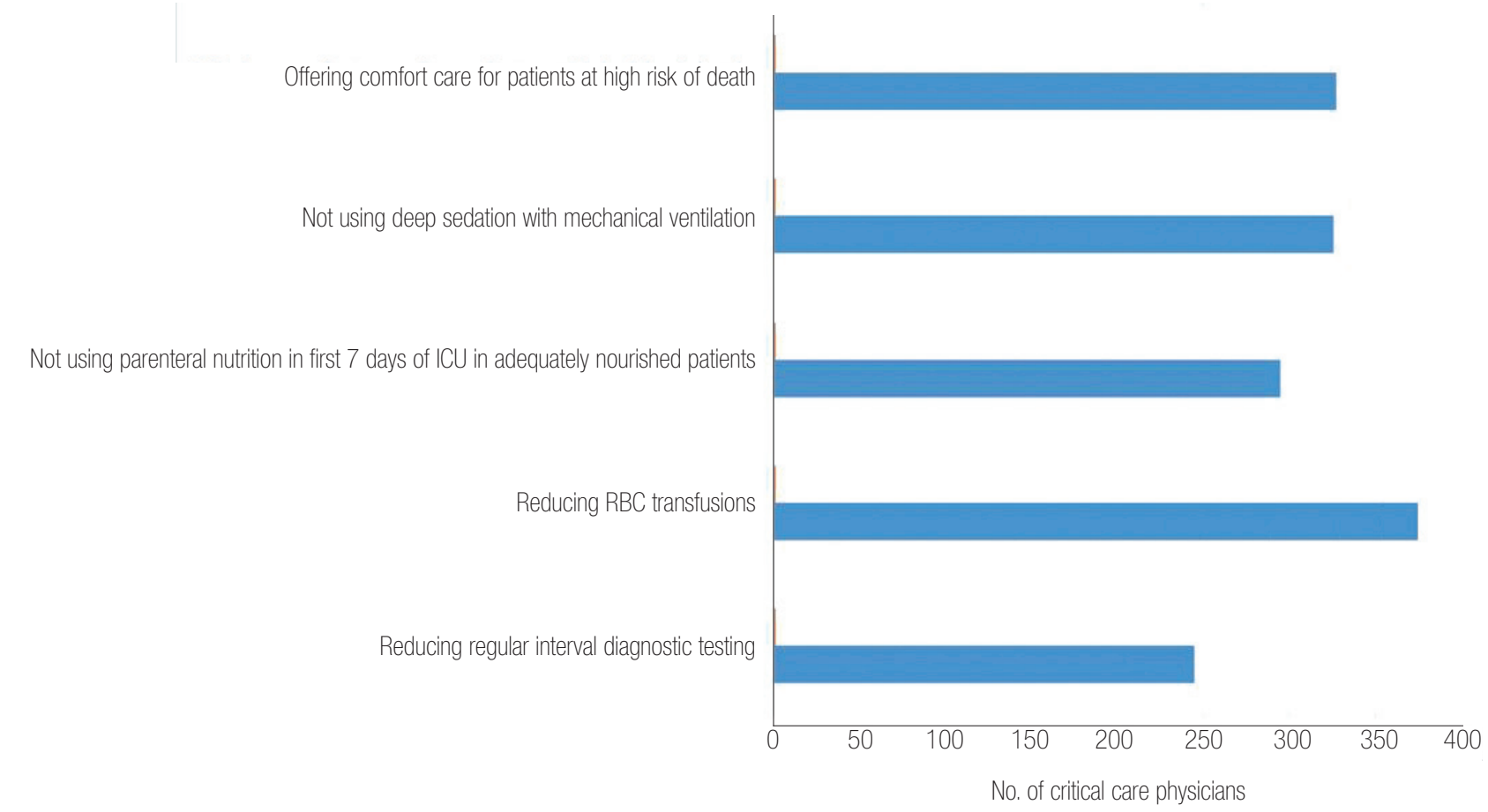

Figure 2. Reports by 432 critical care physicians on implementation efforts targeting the Choosing Wisely ${ }^{\circledR}$ critical care recommendations. ICU: intensive care unit; RBC: red blood cell. Adapted from the Society of Critical Care Medicine [11].

$$
\begin{aligned}
& \text { Included longitudinal tracking using and electronic dash board } \\
& \text { Developed specific electronic medical record orders } \\
& \text { Developed a specific clinical protocol or guideline } \\
& \text { Conducted a specific research initiative } \\
& \text { Conducted a specific quality improvement initiative }
\end{aligned}
$$

Integrated any of the Critical Care Choosing Wisely recommendations in clinical care

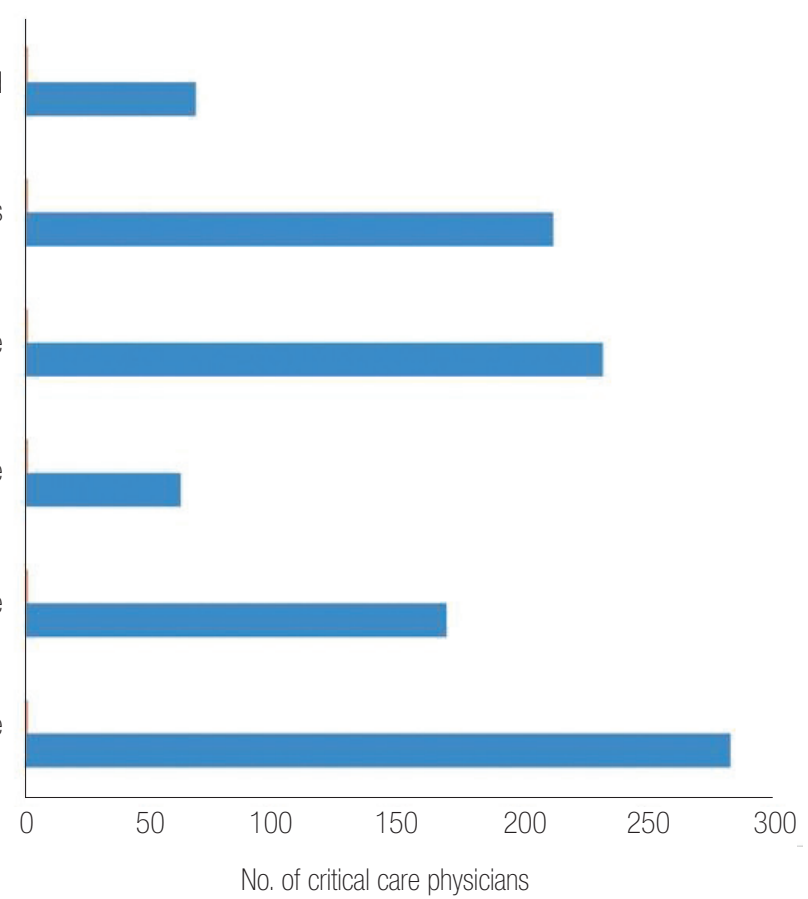

Figure 3. Reports by 432 critical care physicians on how the Choosing Wisely ${ }^{\circledR}$ critical care recommendations had been implemented in clinical practice. Adapted from the Society of Critical Care Medicine [11]. 


\section{STRATEGIES FOR DECREASING UNNECESSARY TESTING IN THE ICU}

Several strategies can be used to implement the Choosing Wisely ${ }^{\circledR}$ recommendations in critical care (Table 1). These include discontinuing the practice of ordering daily laboratory and chest X-ray testing, daily review of the necessity of laboratory tests and chest X-rays for each ICU patient, raising clinician awareness of the impact of unnecessary testing in the ICU, and the use of audit and feedback to promote appropriate ordering of diagnostic testing in the ICU. A recent systematic review on interventions aimed at reducing low-value care identified that the use of clinician feedback, along with education materials was effective in reducing laboratory testing, blood transfusions and imaging studies [12]. Multicomponent interventions were found to have the greatest potential to reduce low-value care including the use of clinical decision support and performance feedback. The review highlighted that further research is needed on the effectiveness of pay-for-performance, insurer restrictions, and risk-sharing contracts to reduce the use of low-value care [13]. Other studies specific to critical care have identified that measures such as clinician education and feedback, education of rotating trainees, adding a check-box to ICU rounds checklist, documenting "no routine lab work indicated for tomorrow" to inform on-call personnel of care

Table 1. Strategies for decreasing unnecessary testing in the ICU

\begin{tabular}{l}
\hline Strategy \\
\hline Discontinue daily lab and X-ray test ordering \\
Daily review of the necessity of lab and X-ray testing for individual ICU patients \\
Raise clinician awareness of the impact of unnecessary testing in the ICU \\
Computerized clinician decision support \\
Individual performance feedback \\
Provider report cards \\
Use of collective audit and feedback to promote appropriate ordering of \\
diagnostic testing \\
Pay-for-performance, insurer restrictions and risk-sharing contracts to reduce \\
the use of low-value care \\
\hline
\end{tabular}

ICU: intensive care unit. plans, implementing a prompt in the electronic ordering system to allow only acceptable indications when ordering routine labs or X-rays, among other measures are effective at increasing clinician awareness and promoting more judicious use of testing for ICU patients [14-16].

\section{CONCLUSIONS}

Promoting high-value care has become an important concept in medical care [17,18], and has significant implications especially for critical care, where unnecessary laboratory and imaging tests can become part of daily practice in the ICU. A number of strategies can be used to reduce unnecessary testing, and to raise clinician awareness of the impact of unnecessary testing in the ICU. Implementing best practices in the ICU such as reducing unnecessary testing can have positive outcomes for patients and decrease healthcare costs.

\section{ORCID}

Ruth M. Kleinpell http://orcid.org/0000-0003-0142-7527

\section{REFERENCES}

1. Peixoto AA Jr, Meneses FA, Barbosa BP, Pessoa LF, Melo RH, Fideles GM. Laboratory routine in the ICU: a practice to be abolished? Crit Care 2013;17(Suppl 3):P12.

2. Choosing Wisely [Internet]. Philadelphia (PA): ABIM Foundation; 2018 [cited 2018 Jan 10]. Available from: www.choosingwisely.org.

3. Cassel CK, Guest JA. Choosing wisely: helping physicians and patients make smart decisions about their care. JAMA 2012;307:1801-2.

4. Choosing Wisely Canada [Internet]. Toronto (ON): University of Toronto, Canadian Medical Association, St. Michael's Hospital; 2018 [cited 2018 Jan 10]. Avail- 
able from: http://www.choosingwiselycanada.org.

5. Consumer Reports [Internet]. Yonkers (NY): Consumer Reports; 2018 [cited 2018 Jan 20]. Available from: http:/www.consumerreports.org/cro/health/doctorsand-hospitals/choosing-wisely/index.htm.

6. Critical Care Societies Collaborative. Choosing Wisely list for critical care: five things physicians and patients should question [Internet]. Philadelphia (PA): ABIM Foundation; [cited 2018 Jan 10]. Available from: http://ccsconline.org/images/CCSC-ChoosingWisely.pdf.

7. Iams W, Heck J, Kapp M, Leverenz D, Vella M, Szentirmai E, et al. A multidisciplinary housestaff-led initiative to safely reduce daily laboratory testing. Acad Med 2016;91:813-20.

8. Bulger J, Nickel W, Messler J, Goldstein J, O’Callaghan J, Auron M, et al. Choosing wisely in adult hospital medicine: five opportunities for improved healthcare value. J Hosp Med 2013;8:486-92.

9. Ivers N, Jamtvedt G, Flottorp S, Young JM, OdgaardJensen J, French SD, et al. Audit and feedback: effects on professional practice and healthcare outcomes. Cochrane Database Syst Rev 2012;(6):CD000259.

10. Canadian Agency for Drugs and Technologies in Health. Rapid response report. Routine blood tests for patients in the intensive care unit: clinical effectiveness, cost-effectiveness, and guidelines. Ottawa (ON): Canada; 2013.

11. Society of Critical Care Medicine. National survey of ICU clinicians assessing knowledge and use of the
Choosing Wisely campaign. Mount Prospect (IL): Society of Critical Care Medicine; 2017.

12. Colla CH, Mainor AJ, Hargreaves C, Sequist T, Morden N. Interventions aimed at reducing use of lowvalue health services: a systematic review. Med Care Res Rev 2017;74:507-50.

13. Colla CH, Morden NE, Sequist TD, Schpero WL, Rosenthal MB. Choosing Wisely: prevalence and correlates of low-value health care services in the United States. J Gen Intern Med 2015;30:221-8.

14. Goddard K, Austin SJ. Appropriate regulation of routine laboratory testing can reduce the costs associated with patient stay in intensive care. Crit Care 2011;15(Suppl 1):P133.

15. Iosfina I, Merkeley H, Cessford T, Geller G, Amiri N, Baradaran N, et al. Implementation of an on-demand strategy for routine blood testing in ICU patients. Am J Respir Crit Care Med 2013;187:A5322.

16. Pageler NM, Franzon D, Longhurst CA, Wood M, Shin AY, Adams ES, et al. Embedding time-limited laboratory orders within computerized provider order entry reduces laboratory utilization. Pediatr Crit Care Med 2013;14:413-9.

17. Pines JM, Newman D, Pilgrim R, Schuur JD. Strategies for integrating cost-consciousness into acute care should focus on rewarding high-value care. Health Aff (Millwood) 2013;32:2157-65.

18. Porter ME. What is value in health care? N Engl J Med 2010;363:2477-81. 